\title{
Fotografia e memória na recuperação histórica de Ivaiporã (PR)
}

\section{Photography and memory in the historical recovery of Ivaiporã (PR)}

\author{
Juliana Mastelini Moyses ${ }^{1}$; Paulo César Boni²
}

\begin{abstract}
Resumo
Este trabalho recupera parte da história de Ivaiporã (PR), sob a ótica dos que ali viveram ou vivem, com o suporte de fotografias. Mais do que ilustrações, as fotografias são usadas como fonte de pesquisa e auxiliares no processo de rememoração histórica. O trabalho analisa o papel que a fotografia exerce como acionadora do "gatilho da memória", aliando o seu uso ao da história oral. A metodologia adotada abrange a revisão bibliográfica, a análise iconográfica e a história oral. Fotografia e história, de Boris Kossoy, e o artigo Vale do Ivaí: Conflitos e ocupação de terras regionais, de Lúcio Boing, são alguns dos referenciais teóricos utilizados. O trabalho consegue, mesmo que parcialmente, dar voz aos que foram alijados do processo histórico e trazer versões oficialmente desconhecidas, mas importantes para a compreensão histórica, além de observar a relação que a fotografia estabelece com a memória.

Palavras-chave: Fotografia e memória. História oral. História de Ivaiporã (PR).
\end{abstract}

\begin{abstract}
The present article recovers part of the history of Ivaiporã (PR) from the viewpoint of inhabitants or ex-residents of the city, using the support of photographs. More than mere illustration, the photographs are used as resource material and support in the process of historical remembrance. This work analyses the role of photographs as "memory triggers", associating its use to oral history. The methodology used consists of the review of literature, the iconographic analysis and the oral history. Boris Kossoy's book Fotografia e História, and Lucio Boing's article, Vale do Ivaí: Conflitos e ocupação de terras regionais were some of the theoretical references used. The study achieves, although partially, its aim of providing a means to those who were kept out from the historical process and bringing to light versions that were unknown but relevant to historical understanding, as well as observing the relation established between photograph and memory.

Keywords: Photography and memory. Oral history. History of Ivaiporã (PR).
\end{abstract}

\section{Introdução}

Este trabalho constitui uma proposta de recuperar parte da história de Ivaiporã (PR), por meio de relatos orais, textos e imagens, com sujeitos de pesquisa que vivenciaram e foram agentes transformadores da história, para observar a relação existente entre fotografia e memória. Com isso - e a partir disso - sistematizam-se e organizar-se seus relatos e

\footnotetext{
${ }^{1}$ Estudante do curso de Comunicação Social - Habilitação Jornalismo da Universidade Estadual de Londrina. E-mail: jumastelinimoyses@gmail.com

2 Doutor em Ciências da Comunicação pela Universidade de São Paulo (ECA/USP). Coordenador do Mestrado em Comunicação pela Universidade Estadual de Londrina. Editor da revista Discursos Fotográficos. E-mail: discursosfoto@uel.br
} 
documentos iconográficos, para que a memória dos que construíram a cidade não se perca; ao contrário, que seja preservada para as gerações futuras.

As fotografias são usadas comomídias “contadoras" de histórias, fontes de pesquisa e instrumento auxiliar para despertar recordações. Nesse sentido, portanto, além de contadoras, são reveladoras de histórias latentes que estavam esquecidas ou adormecidas na memória dos sujeitos de pesquisa entrevistados. Elas assumem um papel importante quando se busca contar a história a partir da perspectiva dos sujeitos que presenciaram os acontecimentos, pois despertam lembranças de lugares, fatos e pessoas que, de outra forma, não seria possível recuperar.

Referenciar a história a partir de memórias e de fotografias, e torná-la acessível, é contribuir para reforçar nas pessoas laços em comum e, assim, preservar a identidade de um povo, seus costumes, cultura e tradição. Isso é possível em razão de que as lembranças individuais carregam muito das características do grupo como um todo. Portanto, abordar peculiaridades é também abordar a história coletiva.

\section{Os Caminhos (Métodos) da Pesquisa}

As metodologias adotadas foram: a pesquisa bibliográfica e documental; a coleta e análise de fotografias; o uso da fotografia como ferramenta acionadora da memória; e a história oral, ou seja, entrevistas com pioneiros e descendentes. A pesquisa bibliográfica foi o primeiro passo e constituiu importante suporte para os demais procedimentos metodológicos.

Num primeiro momento, o foco da pesquisa esteve concentrado na busca de conhecimentos e documentos disponíveis e no levantamento de informações orais e de documentos ainda não disponíveis (em poder de pioneiros). As entrevistas eram divididas em dois momentos. $\mathrm{O}$ primeiro foi destinado às perguntas e respostas, de caráter puramente oral. Quando as respostas se findavam e os entrevistados "não tinham mais o que falar", era acionado o segundo momento da entrevista, que consistia em mostrar-lhes fotografias antigas de Ivaiporã e, a partir de então, observar, gravar e anotar que novas lembranças as fotografias despertavam neles. Com esse procedimento, foi possível estabelecer o papel da fotografia como acionadora do gatilho da memória, pois sorrisos, olhares, emoções e novas - e muitas - histórias surgiram a partir do momento em que os entrevistados olharam para as fotografias.

Após o levantamento das informações documentais e orais, passou-se para a parte da organização, classificação e sistematização dos dados e imagens levantadas e posterior análise do papel da fotografia na recuperação histórica, como fonte de consulta e dissipação de dúvidas, bem como na função de auxiliar da memória, como despertadora de novas lembranças.

"Toda fotografia tem atrás de si uma história." (KOSSOY, 2001, p. 45). As fotografias são um importante instrumento para contar a história de um grupo de pessoas ou de um lugar. Mais do que a expressão estética de um momento recortado no tempo, elas contam muito do ambiente e da situação vivida. Desse recorte, carregam características peculiares que contam muito dos hábitos, costumes e rotina de um povo, e aguçam a memória. As fotografias, portanto, são guardiãs de uma realidade, mesmo que parcial. Martins (2008, p. 36) fala da relação entre fotografia e realidade.

\begin{abstract}
[...] a fotografia nutre a sua interpretação por uma contínua remessa ao real, que não se deixa congelar, que não interrompe o seu fluxo e que, por sua vez, agrega e redefine significações ao que só aparentemente é um 'congelamento' de imagem e, nesse sentido, um 'retrato' da sociedade em certo momento.
\end{abstract}

Kossoy (2007) fala que a carga documental da fotografia, fundamental para a recuperação histórica, está na sua força expressiva de fixar a memória individual e coletiva ao gravar microaspectos dos locais, fatos e personagens. Hoffmann (2010, p. 2122) acrescenta que a fotografia ajuda a compreender o período pesquisado e obter novas informações. 
A imagem fotográfica pode ser utilizada para obter informações inéditas ou para confrontar informações obtidas por outros tipos de documentos. Elas permitem desvendar aspectos que não ficam claros em outras formas de registro e ajudam a recuperar a história daqueles que não deixaram escritos ou depoimentos.

A fotografia é um documento que ajuda a contar a história a partir da presentificação de um momento visual vivido no passado. Ela familiariza um lugar, um instante a alguém que não esteve ali, naquela época. O recorte fotográfico atualiza um momento do passado (um recorte apenas) a cada novo olhar. Segundo Kossoy (2001, p. 27), as fotografias têm a capacidade de "registro preciso do aparente e das aparências".

Por isso, fotografia e memória mantêm entre si uma relação muito forte - e daí a importância de se aliar à história oral - nesse trazer à tona uma situação do passado. A fotografia existe justamente para servir à memória, pois ela foi produzida para preservar aquele momento de alguma forma, num recorte de papel. Martins (2008, p. 43) fala que a fotografia se propõe não como memória, mas como um apontamento da memória, "como lembrete do que se perdeu no cotidiano, na banalização, na secundarização de certos acontecimentos, e não se quis perder."

Esse lembrete é acionado quando as pessoas observam uma fotografia e presentificam uma cena que os antepassados quiseram preservar. Borges (2005, p. 78-79) ressalta que:

Os homens e mulheres que se dedicam a pensar e a refletir os diferentes campos da dinâmica social não podem desconhecer o poder das imagens. Para além de sua dimensão plástica, elas nos põem em contato com os sistemas de significação das sociedades, com suas formas de representação, com seus imaginários.

A memória despertada pela fotografia ajuda a construir um discurso histórico, posto que cabe a cada cidadão - e a todos - a formação do lugar onde se vive. Cada família que saiu do lugar onde estava e mudou-se para Ivaiporã no intuito de construir a vida e criar os filhos; cada pessoa que com a enxada e a serra nas mãos ergueu sua vida onde nada existia, que se formou ao mesmo tempo em que a cidade, tem muito a dizer. Neste sentido, dar voz aos atores esquecidos na sociedade é colocá-los em seu devido lugar: de "fazedores" da história e construtores da cultura. Pois, mesmo que não apareçam, a história só pôde ser construída graças ao seu trabalho.

Conhecer as histórias de quem ajudou a construir Ivaiporã é conhecer também um pouco de sua história coletiva, pois elas falam muito do conjunto. Um instrumento para isso é a história oral, que auxilia a tentativa de dar voz aos anônimos que têm muito que contar. Thompson (1992, p. 22) fala que a história oral não é necessariamente um instrumento de mudança, mas pode, sim, ajudar a transformar as concepções de história. "Pode ser utilizada para alterar o enfoque da própria história e revelar novos campos de investigação [...] pode devolver às pessoas que fizeram e vivenciaram a história um lugar fundamental, mediante suas próprias palavras."

Além de dar espaço de expressão àqueles que vivenciaram a história, Boing (2007) aponta que a história oral possibilita uma interpretação mais aberta às diferenças, o que serve de base para o confronto de pontos de vista acerca de um mesmo acontecimento. Passa-se a ouvir não só uma versão dos fatos, mas várias versões, o que facilita a compreensão da realidade.

Meihy (2002) admite que os depoimentos sejam repletos de interferências emocionais e vieses variados. Porém, para ele, o que interessa à história oral está na emoção e na subjetividade com que o fato é narrado. Considera-se a versão que cada um tem de um mesmo fato e como aquele acontecimento se caracterizou para cada um. O historiador diz também que muitos autores do uso da história oral garantem estar na busca da experiência o objetivo central da história oral, e não na busca da verdade. Em seguida, acrescenta que a história oral se 
concentra na captação de experiências de vida de pessoas dispostas a falar sobre suas vidas. Nesse sentido, "quanto mais elas os contarem a seu modo, mais eficiente será seu depoimento." (MEIHY, 2002, p. 51).

\section{Ivaiporã em fotografias}

Jovem cidade do centro norte do Paraná, Ivaiporã acolheu pessoas de diferentes lugares em busca de melhor qualidade de vida ou simplesmente um lugar para viver. Sua ocupação se deu com a vinda de pessoas de vários estados, com o encontro das três frentes de colonização que marcaram a ocupação do Paraná: frente tradicional, frente do norte e frente sulista. Cada frente representava uma cultura e ocupou um espaço geográfico diferente. Por conta disso, se fala da existência de "três paranás", que se encontraram na região de Ivaiporã.

Os primeiros a se dirigir para a região foram os chamados caboclos, no final da década de 30 , que adentravam nas matas e abriam lugares novos no sertão (BOING, 2007). O jeito dos caboclos causou estranhamento nos catarineneses, que chegaram ao final dos anos 40. Os caboclos por sua vez estranhavam o jeito de lidar dos catarinenses, pois estes chegavam comprando suas posses de terras e os obrigavam a sair das terras que ocupavam sem documentação. Para os catarinenses, a terra tinha noção de posse, tanto que a família da pioneira Adelina Bitencourt chegou em 1948 em busca de mais terras para comprar, posto que em Santa Catarina a família morava num sítio, "mas existia pouca terra", conta ${ }^{3}$.

Imigrantes também se dirigiam para a região, atraídos pelas terras férteis e os grandes espaços para produzir. A esperança de encontrar um lugar que fosse seu, onde pudessem viver do trabalho na terra, atraiu muitos dos que eram estimulados por aqueles que já ali se encontravam.
A figura 1 retrata a mata que existia na região na década de 40, quando teve início o processo de colonização. A mata traz consigo a ideia de fertilidade das terras, já que floresta só cresce em solo fértil. Onde existia mata, plantar era sinônimo de produção garantida. Segundo os entrevistados, de Porto Ubá a Ivaiporã tudo era sertão.

Figura 1- Bráulio Barboza, ao centro, um dos donos da Cia. Ubá

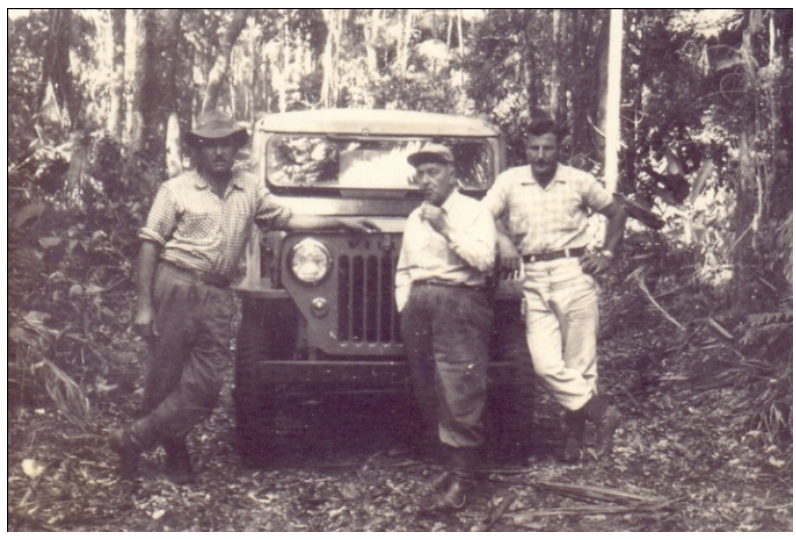

Fonte: Acervo Prefeitura Municipal de Ivaiporã

Por sua força expressiva, de mostrar as qualidades das terras, a fotografia foi usada como propaganda para atrair compradores. O senhor ao centro é Bráulio Barboza, um dos proprietários da colonizadora que se instalou na região no final da década de 40 para lotear os terrenos da Fazenda Ubá, nome do lugar onde nasceu a cidade.

Os homens que pousam para a fotografia se apresentam numa situação de superioridade em relação ao restante do cenário. Toda mata está ao fundo, submetida à vontade do homem, sustentada pela força representativa do automóvel. E era isso que se pretendia transmitir com o intuito de atrair cada vez mais gente para a recém-colonizada região. Vale lembrar que na década de 40 - e até a década de 70 - o automóvel era um indício de status e trazia a ideia de prosperidade.

\footnotetext{
${ }^{3}$ Adelina Bitencourt. Entrevista concedida a Juliana Mastelini Moyses em 27 de julho de 2010.
} 
Lúcia Santaella (2009, p. 42) fala que fotografias antigas "de pessoas, casas e cidades amadas produzem no observador sentimentos de nostalgia e mesmo de ternura. Nostalgia pela evidência de escoamento de um tempo que foi indo embora para sempre. Ternura porque até o coração mais duro amolece diante daquilo que não voltará jamais".

Para além da nostalgia e ternura, uma fotografia é capaz de aguçar, em quem a observa, sentimentos negativos. A figura 1 foi capaz de despertar em uma das entrevistadas o sentimento de repulsa ao ver o dono da Companhia Colonizadora Ubá. A fotografia the trouxe à memória, a situação vivida por sua família quando da chegada da colonizadora. As famílias já estavam alojadas nas terras quando a Ubá chegou reivindicando o reconhecimento da posse das terras, "obrigando-os", segundo Maria José Machado ${ }^{4}$, a pagar a terra pela qual já haviam pago.

Percebemos claramente na fala dos entrevistados, mesmo quando tentavam minimizar os acontecimentos, o impasse que significou a instalação da colonizadora na região. Ela se instalou e exigiu o pagamento das terras. Aqueles que não concordavam ou não tinham como pagar, eram expulsos, "jogados" do outro lado do rio Ivaí com mudança e tudo. Antes, porém, os funcionários da Companhia Ubá davam alguns "avisos", devastando plantações inteiras. Esses funcionários eram chamados de "gafanhotos de aço". Maria José conta que certa vez sua família foi ao sítio vizinho para fazer pamonha e aproveitar a plantação inteira de milho que havia sido cortada.

A família de Maria José não esperou que a companhia destruísse sua plantação ou a expulsasse: deixou as terras e foi trabalhar - como empregados - em outras propriedades rurais. Apesar desse impasse, era notória a nostalgia com relação ao período anterior ao incidente, quando sua família cultivava a terra que dizia ser sua. Nesse período, segundo ela, a família produzia tudo o que precisava para subsistência.

Essa característica, a de despertar sentimentos, mostra que além de sua carga documental, a fotografia é um importante instrumento de recuperação histórica aliado à história oral. Com o despertar de sentimentos, o entrevistado se dispõe a contar aspectos que passariam despercebidos não fosse o impulsionar da fotografia.

A mata visível na figura 1 foi sendo derrubada à medida que o lugar foi sendo desbravado, cedendo espaço para plantações e estradas. As enormes árvores, depois de arrancadas com ferramentas manuais como enxadas e picaretas, eram queimadas. Com o objetivo de explorar cada vez mais as terras, o desmatamento prosseguiu de tal forma que a mata foi quase completamente devastada.

A figura 2, datada de 1966, mostra como em menos de duas décadas, em alguns lugares, a floresta já estava quase totalmente devastada. A imagem é da balsa sobre o rio Ivaí; o que restava de mata está ao fundo. A fotografia retrata a caravana de catequistas do Sagrado Coração de Jesus e de padres de Prudentópolis (PR) que veio a Ivaiporã para a bênção da pedra fundamental da construção do colégio Santa Olga (40 ANOS..., 2004).

Figura 2- Balsa sobre o Rio Ivaí (1966).

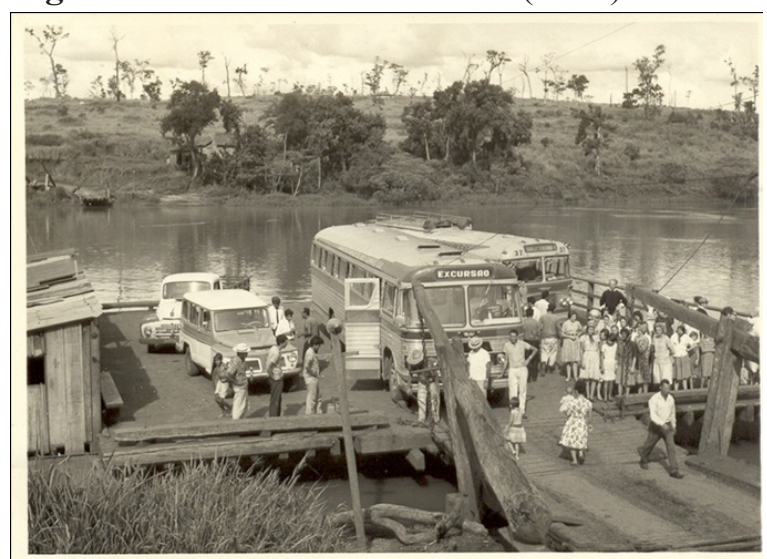

Fonte: Acervo Prefeitura Municipal Ivaiporã

${ }^{4}$ Maria José Machado. Entrevista concedida a Juliana Mastelini Moyses em 16 de fevereiro de 2011 
A importância da balsa estava no fato de que as pessoas dela dependiam para atravessar o rio, pois a ponte só foi construída por volta de 1970 . A balsa servia para escoar cereais, trazer produtos necessários para a subsistência, e para o transporte de passageiros. A viagem, que já demorava em razão da incipiência das estradas, atrasava ainda mais pela espera e morosidade da balsa.

Quando não era possível atravessar pela balsa, os moradores apelavam para medidas alternativas. Adelina Bitencourt conta que, certa vez, uma enchente muito forte carregou a balsa. Seu marido, que havia ido buscar mantimentos em Apucarana $(\mathrm{PR})$, teve que atravessar o rio por canoa. A balsa era fundamental, pois muitas famílias se deslocavam para Londrina (PR) ou Apucarana (PR) para comprar o que era necessário.

Herondy Anunziato ${ }^{5}$ recorda que a balsa era puxada à mão, por meio de um cabo de aço, com a ajuda de um pedaço de pau e uma forquilha. Pode-se observar os cabos de aço do lado direito da fotografia e um homem de chapéu, manipulando uma corrente, provavelmente algum mecanismo da balsa.

Nas décadas de 40 e 50, as pessoas se dirigiam exclusivamente para os sítios; a cidade só se formaria anos mais tarde. O lugar em torno do qual a cidade foi crescendo possuía poucas casas ao longo da atual avenida Brasil. Essas casas eram também vendas, nas quais aqueles que moravam nos sítios compravam o que precisavam. A primeira sala da casa era a venda, a família morava nos cômodos do fundo. Os compradores que chegavam a cavalo amarravam o animal nas cercas ao redor da casa.

Esta fotografia (Figura 3) é a imagem mais lembrada quando se pergunta como era Ivaiporã em seu início, tempo em que o lugar era chamado de Sapecado. Ela traz implícita uma ideia de contradição entre a promessa de urbanidade representada pela rua e o início da construção de casas; e o rural que ainda era realidade, mostrado, dentre outras, pela floresta ao fundo e a rua sem pavimentação.

Figura 3- Avenida Brasil (1954).

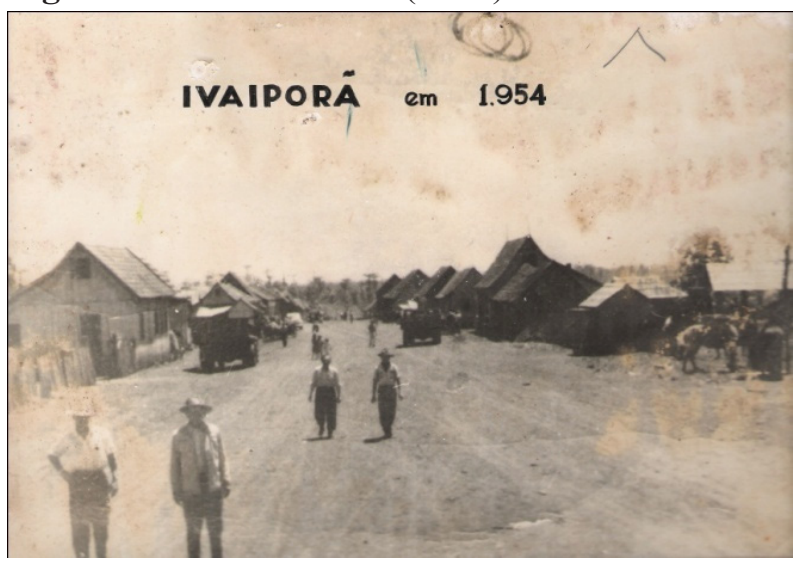

Fonte: Acervo Jornal Paraná Centro

Ao redor dessa rua foi-se formando a cidade. Ali ficavam as casas comerciais e os hotéis. A imagem mostra como o terreno era variado, alguns lugares de mata e outros não. A floresta, dantes abundante, agora só pode ser vista ao fundo. O lugar onde foram construídas a rua e as casas passou por uma queimada, deixando o terreno limpo. Deve-se a essa queimada a primeira denominação do lugar: Sapecado.

Apesar de fazer parte da memória coletiva dos cidadãos, encontrar esta fotografia foi muito difícil. Muitas pessoas possuem sua reprodução em pintura. A única cópia da fotografia a que tivemos acesso já estava envelhecida e com algumas marcações que provavelmente não foram feitas nem por seu autor nem por seu dono.

Outra fotografia não tão conhecida - que retrata o mesmo lugar - é a da figura 4. Nela é possível perceber com mais clareza aspectos arquitetônicos, urbanísticos, sociais, ambientais da cidade que se formava. As casinhas mostram como eram as

${ }^{5}$ Herondy Anunziato. Entrevista concedida a Juliana Mastelini Moyses em 28 de julho de 2010 
construções, tanto nos sítios como na cidade, todas em madeira, inclusive os telhados, feitos de tábuas cortadas pequenas e pregadas uma sobre a outra. Maria José conta que as tábuas eram excelentes para cobrir as casas. "A tabuinha se pregava e a capa em cima pra não entrar chuva. Podia cair tormenta, podia cair pedra, aquilo só escutava o barulho da chuva lá fora", explica.

Figura 4 - Avenida Brasil (1954).

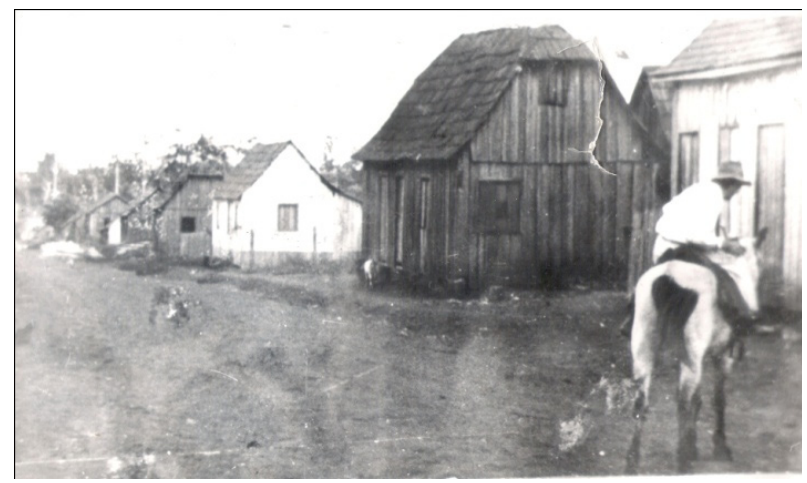

Fonte: Acervo Biblioteca Municipal Ivaiporã.

Do lado direito da imagem (Figura 4) aparece um homem descendo de um cavalo. Esses animais, e as carroças, representavam os meios de transporte quase exclusivos da época, principalmente dos que moravam nos sítios e precisavam ir para a cidade em busca de produtos. Os carros eram raros e os únicos que conseguiam se locomover nos terrenos acidentados eram os jeeps. Quem não possuía cavalo ou carroça fazia o trajeto a pé. As mercadorias vendidas ou trazidas de outras cidades eram transportadas por caminhões.

Tanto nessa imagem (Figura 4) quanto na anterior (Figura 3) só aparecem homens, todos vestem chapéu. Numa análise primária podese supor que o chapéu tinha a única função de proteção do sol, porém a pioneira Tusnelda Goedert conta que o chapéu na época representava a masculinidade, os homens precisavam usar chapéu.
A próxima imagem (Figura 5) mostra o motor a vapor da Serraria Brasil. Seu funcionamento era similar ao de uma locomotiva de trem, ou seja, a lenha era colocada para queimar e o calor produzido pela queima esquentava a água que então se transformava em vapor (COMEMORAÇÃO..., 2009). A fotografia é datada de 1962, ano em que a Serraria Brasil iniciou suas atividades. Este motor foi utilizado por 15 anos. Mesmo depois da instalação - precária e insuficiente, no início - da energia elétrica na cidade, a serraria continuou utilizando o motor.

Figura 5 - Motor a vapor da Serraria Brasil (1962).

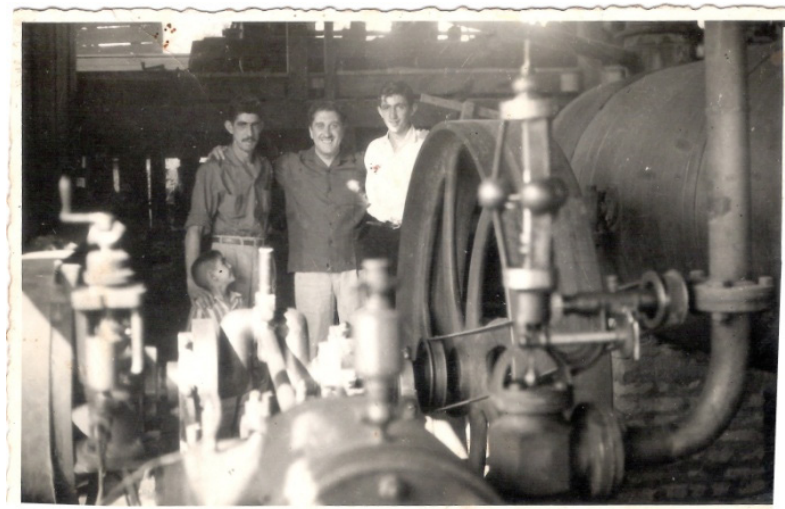

Fonte: Acervo da família Martos.

O homem à esquerda, na figura 5, é Pedro Martos, dono da Serraria Brasil, ao lado de amigos e filho. A composição da fotografia foi elaborada de modo a destacar não as pessoas, mas o motor a vapor, que representava à época o lançar mão do uso de avançada tecnologia. A valorização do primeiro plano permite perceber os detalhes da máquina, mas conota que ela, por si só, nada vale: é preciso que o homem a controle. Outro aspecto interessante a observar-se na fotografia é a luz que o fotógrafo utiliza. Apesar dos personagens se encontrarem em um ambiente interno, a luz é externa e ilumina o primeiro plano, ou seja, a máquina; os homens, 
ao fundo, estão na área de sombra, à exceção do homem à direita, cuja camisa está iluminada. Isso conota que o principal aspecto que o fotógrafo queria captar era a máquina, não os homens.

Para o restante da cidade, a energia elétrica era fornecida por meio de um motor estacionário. As pessoas recebiam energia até a meia noite, depois disso as luzes se apagavam e com ela o grande barulho do motor. Quando a eletricidade chegou à cidade, as pessoas estranhavam tanto o silêncio como a nova tecnologia. Inês Ishii ${ }^{6}$ conta que mesmo depois de ter luz elétrica em casa, quando levantava de madrugada acendia uma vela para iluminar o ambiente.

As igrejas primeiramente foram construídas nas localidades rurais, posto que as primeiras formações habitacionais se deram nos sítios e fazendas. No começo, a visita do padre era esperada e só acontecia algumas vezes por ano. As escolas ficavam nos fundos das igrejas. As professoras eram então responsáveis tanto pela alfabetização, como pela catequização e preparação das crianças para a primeira comunhão. Além disso, eram as professoras que inclusive preparavam as reuniões na igreja.

Ao observar a figura 6, é possível deduzir que as classes eram multisseriadas, ou seja, comportavam diversas séries, realidade ainda presente em algumas escolas rurais. Na maioria das vezes só havia uma professora, como na situação fotografada, para vários alunos de idades e séries diferentes. Isso pode ser visto pela variação de tamanho das estudantes, desde crianças muito pequenas até moças que se confundem com a professora.

Tusnelda Goedert conta que quando se mudou para um sítio perto do rio Pindauvinha, não era professora, só havia cursado as séries iniciais. "Mas como em terra de cego quem tem um olho é rei", brinca, ela foi chamada para lecionar.
Figura 6 - Estudantes de uma escola rural de Ivaiporã.

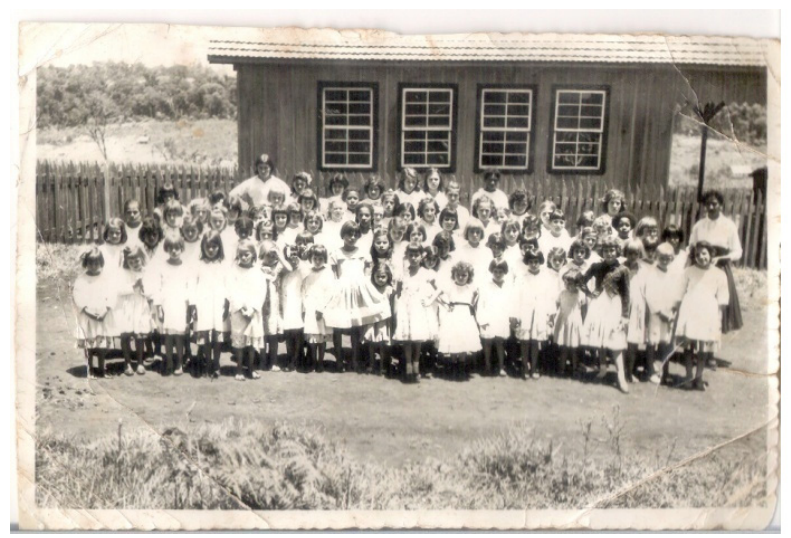

Fonte: Biblioteca Municipal de Ivaiporã

Na fotografia (Figura 6), é possível perceber a distinção social pela roupa. Todas usam vestidos brancos, porém nota-se que as meninas com os vestidos mais bem acabados estão do lado direito, todas usam sapatos e algumas delas fazem pose, com a mão na cintura e o pé esticado em posição de destaque. À esquerda, a realidade é outra: meninas com vestidos simples e guarda-pós por cima, possivelmente para esconder o vestido, sem calçados e em posição de submissão se comparadas com as meninas da direita.

As escolas, normalmente, ficavam juntas às igrejas, desde a primeira capela construída (Figura 7). Ela se localizava onde hoje é o Largo Dom Pedro II, no centro da cidade, próximo de onde foi construída a igreja matriz Bom Jesus, uma das fontes de pesquisa deste trabalho. A igreja era pequena, toda em madeira e rodeada pela mata. Alguma celebração estava sendo realizada no momento em que a imagem foi tomada, porém não foi possível identificar, junto aos entrevistados, do que especificamente se tratava. Parece que o fotógrafo captou o momento em que as pessoas caminhavam para a igreja, inclusive é possível ver uma criança um pouco mais distante do grupo.

${ }^{6}$ Inês Ishii. Entrevista concedida a Juliana Mastelini Moyses em 26 de julho de 2010. 
Figura 7 - Primeira capela de Ivaiporã.

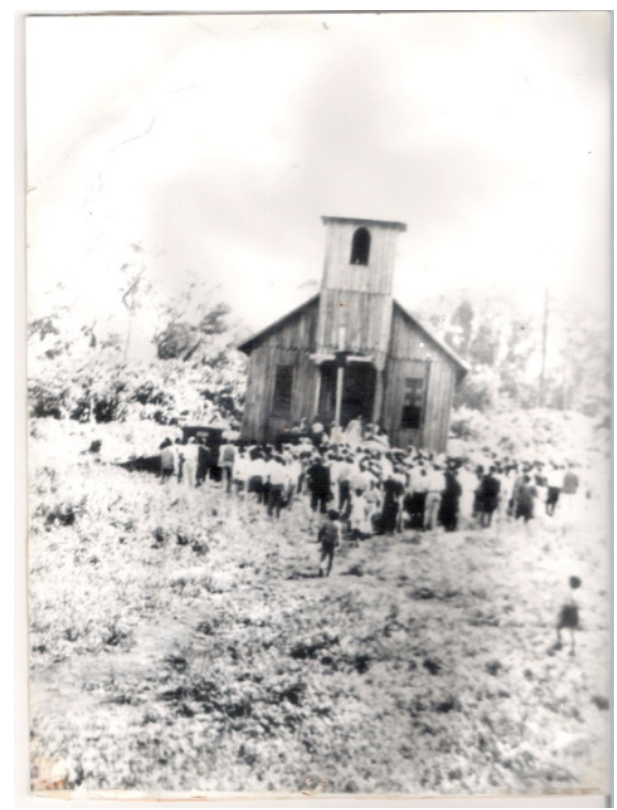

Fonte: Biblioteca Municipal de Ivaiporã

A composição um pouco inclinada, provavelmente pela irregularidade do terreno em que o fotógrafo apoiou sua câmera, dá destaque para a igreja, mas deixa o plano aberto, valorizando o ambiente em que se encontra a construção. Nesta fotografia, percebem-se as características principais das capelas dessa época, por volta das décadas de 50 e 60: pequenas construções em madeira, com uma torre à frente e um cruzeiro.

\section{Considerações Finais}

A fotografia não desperta os mesmos sentimentos em todas as pessoas. Cada um reage à sua maneira, trazendo muito de suas características pessoais. Portanto, traçar até que ponto a fotografia é capaz de fazer despertar para um acontecimento, uma situação, é de complexo e pode resultar numa generalização pretensiosa. Falar do ser humano é falar de peculiaridades e não de generalizações.

Porém é possível afirmar que ninguém fica alheio à fotografia, ela sempre desperta algum sentimento. E são esses sentimentos que vão ajudar a memória na tentativa de recuperar a história para que ela não se perca. Descobrir o que se refere a cada um é descobrir aos poucos o que diz respeito a todos. Por isso, unir fotografias e oralidade para recuperar a história de um lugar, de um povo, é um instrumento muito eficiente. Foi esse o instrumento utilizado neste trabalho. E ele possibilitou chegar não só a questões esquecidas, mas também a aprofundar aspectos e fatos da história de Ivaiporã, seus pioneiros e seus cidadãos. A partir disso, foi possível perceber também que a memória, tanto imagética quanto histórica da cidade está dispersa, e que é preciso aglutiná-la, para que as pessoas possam conhecê-la e democratizá-la.

Um dos papéis da história é criar nas pessoas o sentimento de identificação com aquelas que compartilham aspectos da vida. Mas, para que a história crie identificação, é preciso conhecê-la. Este trabalho foi desenvolvido com este intuito: conhecer um pouco mais sobre as pessoas e aspectos de seu lugar comum, e, quem sabe assim, fortalecer a identidade do lugar pela preservação da memória.

\section{Referências}

40 ANOS de história: 1964 a 2004. Revista Comemorativa dos 40 Anos do Colégio Santa Olga, Ivaiporã, 2004.

BOING, L. Vale do Ivaí: conflitos e ocupação das terras regionais. 2007. Disponível em: <http://www. diaadiaeducacao.pr.gov.br/portals/pde/arquivos/ 582-4. pdf $>$. Acesso em: 20 mar. 2010.

BORGES, M. E. Ls. História e fotografia. 2. ed. Belo Horizonte: Autêntica, 2005.

COMEMORAÇÃO 48 anos de Ivaiporã. Jornal Paraná Centro, Ivaiporã, 16 nov. 2009. Edição Especial.

HOFFMAN, M. L. Guardião de imagens: "memórias fotográficas" e a relação de pertencimento de um pioneiro com Londrina. 2010. Dissertação (Mestrado em Comunicação Visual) - Universidade Estadual de Londrina, Londrina.

KOSSOY, B. Fotografia e história. 2. ed. Cotia: Ateliê, 2001.

Os tempos da fotografia: o efêmero e o perpétuo. Cotia: Ateliê, 2007. 
MARTINS, J. S. Sociologia da fotografia e da imagem.

São Paulo: Contexto, 2008.

MEIHY, J. C. S. B. Manual de história oral. São Paulo: Loyola, 2002.

QUIEZI, S. A. Companhia Ubá: colonização e ocupação do território entre os rios Ivaí e Corumbataí (19391970). 1999. Monografia (Especialização em História) Faculdade de Filosofia de Mandaguari, Mandaguari.

SANTAELLA, L. Fotos também se leem. Carta na Escola, São Paulo, n. 34, p. 42-45, mar. 2009.

THOMPSON, P. A voz do passado: história oral. São Paulo: Paz e Terra, 1992. 